TABLE 12

\title{
RENTAL EQUIVALENT ON A LEASE
}

$$
\frac{r}{1-(1+r)^{-n}} \times \frac{1-\left(\frac{1+g}{1+r}\right)^{n}}{r-g}
$$

TABLE 13

\section{RENTAL EQUIVALENT ON AN ANNUAL TENANCY}

$$
\begin{array}{ll}
\frac{1-(1+r)^{-n}}{r} \times \frac{r-g}{1-\left(\frac{1+g}{1+r}\right)^{n}} \\
\\
\text { Redemption yields } & 3-20 \% \text { @ } 1 \% \\
& 22 \%, 25 \% \\
\text { Growth rates } & 1-6 \% \text { @ } 1 \% \\
& 8 \%, 10 \% \\
\text { Lease periods } & 3,5,7,10,14, \\
\text { (years) } & 21,25,28,35, \\
& 42,50
\end{array}
$$

